\title{
eParticipation Initiatives in Europe: Learning from Practitioners
}

\author{
Eleni Panopoulou, Efthimios Tambouris, and Konstantinos Tarabanis \\ University of Macedonia, Egnatia 156, \\ 54006 Thessaloniki, Greece \\ \{epanopou, tambouris, kat\} @uom.gr
}

\begin{abstract}
The main objective of this paper is to investigate the use of Information and Communication Technologies (ICT) and derive the success factors of eParticipation initiatives according to the practitioners' view. For this purpose, a European survey took place using questionnaires. The results suggest that the tools and technologies currently employed are mainly general purpose and not specifically designed for eParticipation. The results further suggest that success factors can be grouped together in seven categories, namely commitment by the government; usability; combining online with offline channels; a thorough communication and promotion plan; security and privacy; organisational issues; and topics' complexity and quality of participation. A comparison with published success factors of eGovernment initiatives suggests there are similarities but also significant differences. We anticipate that the results will be of interest to practitioners as they distil others experience in a usable form. We further anticipate that this work will be of interest to researchers as it will enable validating eParticipation evaluation models.
\end{abstract}

Keywords: eParticipation Initiatives, Evaluation, Good Practice.

\section{Introduction}

Electronic participation (eParticipation) can be defined as "the use of Information and Communication Technologies (ICT) to broaden and deepen political participation by enabling citizens to connect with one another and with their elected representatives" [1]. eParticipation is currently promoted by relevant policies and initiatives at all levels; for example, "Strengthening Participation and Democratic Decision-Making in Europe" is one of the actions that the European Commission has launched within the i2010 eGovernment Action Plan "Accelerating eGovernment in Europe for the Benefit of All" [2].

The potential for ICT to increase political participation and to address the growing democratic deficit across Europe has long been the subject of academic debate [3]. However, only relatively recently there has been sufficient practical design and application of eParticipation suggesting that this potential could be considered within a real-world context [4]. This arrival of more sophisticated information systems has produced a growing community of research and practice that is investigating 
eParticipation. Current investigation includes among others understanding the role of technology in public participation and learning from the experience of others.

Work of academics includes frameworks and approaches to better understand eParticipation as an academic domain. At the same time however there is a lack of field studies, thus a lack of the practitioners' view.

The main objective of this paper is to investigate the use of ICT and derive the success factors of eParticipation initiatives according to the practitioners' view. For this purpose, a survey of eParticipation initiatives across Europe and at different levels (from local to international) was carried out. We anticipate that the results will be of interest to practitioners as it will distil others experience in a usable form. We further anticipate that this work will be of interest to researchers as it will enable validating theoretical models and academic frameworks based on real data.

The rest of this paper is organised as follows. In section 2 we outline relevant work. In section 3 we present the methodological approach used for this study. In section 4 we present the main results while in section 5 the main conclusions are discussed. Finally, appendix A provides a list of the European eParticipation initiatives investigated in this study.

\section{2 eParticipation Evaluation Frameworks}

During the last few years, a number of frameworks and models have been proposed in scientific literature attempting to analyse the eParticipation domain. These include a characterisation framework by Macintosh [5], a domain model by Kalampokis et al [6] and the eParticipation analytical framework [7]. More recently, the need for specific eParticipation evaluation frameworks has been identified. For example, Aichholzer and Allhutter [8] suggest there is an "evaluation gap" as resources, such as time, money and effort, are not being taken into consideration in eParticipation frameworks. In the rest of this section a number of frameworks for evaluating eParticipation are presented.

In 2000, Rowe and Frewer presented a framework for evaluating public participation methods [9]. Although it was not proposed for eParticipation, this framework specified a number of theoretical criteria that are essential for effective public participation and divided them in two types: acceptance criteria and process criteria. Acceptance criteria, namely representativeness, independence, early involvement, influence, and transparency, offer a measure of acceptability by the wider public, while process criteria, namely resource accessibility, task definition, structured decision making, and cost-effectiveness, offer a measure of effectiveness.

An attempt to produce a framework for assessing not only eParticipation projects but also eParticipation tools has been made by Tambouris et al [10]. The proposed framework suggests there are three main layers of analysis that need to be addressed: participation areas, tools utilised and technologies used. A template has been produced based on these three levels in order to document and assess eParticipation projects.

An evaluation framework for eParticipation has been suggested by Macintosh and Whyte [11]. The proposed evaluation criteria cover three different perspectives of an eParticipation initiative, namely the democratic, project and socio-technical 
perspective. The democratic perspective considers the overarching democratic criteria that the eParticipation initiative is addressing, while the project perspective examines in detail the specific aims and objectives of the eParticipation initiative. Finally, the socio-technical perspective considers to what extent the design of the ICTs used directly affects the outcomes. Under each evaluation perspective a number of criteria have been identified as follows (a) Democratic Criteria: Representation; Engagement; Transparency; Conflict and consensus; Political equality; and Community control, (b) Project Criteria: Engaging with a wider audience; Obtaining better informed opinions; Enabling more in-depth consultation; Cost effective analysis of contributions; and Providing feedback to citizens, (c) Socio-technical Criteria: Social acceptability; Usefulness; and Usability.

The above framework proposed by Macintosh and Whyte has been adapted and expanded within DEMO-net [12]. Specifically, the DEMO-net approach keeps the same three perspectives, most of the criteria, and introduces sub-criteria as follows: (a) Project perspective: Engaging with a wider audience; Obtaining better-informed opinions; Scope of deliberation; Effectiveness; Feedback; Process quality; and Sustainability, (b) Socio-technical perspective: Social acceptability; Usefulness; and Usability, (c) Democratic perspective: Representation; Engagement; Transparency; Conflict and consensus; Political equality; and Community control.

\section{Methodological Approach}

To achieve our objectives we conducted a European survey. More specifically, we employed a three-step methodological approach as follows.

1. We identified eParticipation initiatives from across Europe by employing three different methods: desktop research ${ }^{1}$, databases of websites and award nominations ${ }^{2}$, and our network of experts and key actors in the field. Overall, we identified 255 initiatives from 23 European countries and were able to collect contact data for 230 of them. An extensive analysis of these cases is presented elsewhere [13] [14].

2. We drafted a questionnaire to be filled in by the owners of the initiatives. The questions were selected based on a preliminary literature review of eParticipation evaluation frameworks (outlined in section 2) as well as of good practice criteria definitions in different contexts, mostly focused in eGovernment good practice and relevant awards for eGovernment initiatives.

3. We contacted the owners of the 230 gathered initiatives and kindly requested their participation in our questionnaire survey. This phase lasted 3 to 4 months as we had to repetitively request participation and ensure adequate time to owners to draft their answers. As a result, we gathered completed

\footnotetext{
${ }^{1}$ For example, initiatives mentioned in the literature as well as initiatives identified through web surfing and the help of search engines. Especially for the European level, extensive desktop research was conducted within the numerous EU institutions, the College of Commissioners, the EU policy documents as well as political parties and civil societies.

${ }^{2}$ For example, epractice.eu, e-participation.net, eEurope Awards for eGovernment, UK eGovernment National Awards, Stockholm Challenge awards, etc.
} 
questionnaires from 40 different eParticipation initiatives originating from 12 different European countries and addressing all different levels of participation: international, European, national, regional and local audiences. Although the response rate is low $(17.4 \%)$ we believe that it is sufficient for the purposes of this study. It should also be noted that this percentage would be higher if a screening of initiatives was performed, e.g. if we excluded initiatives that were officially terminated etc.

An important limitation of the study is the language of communication. Although a large number of languages were employed for identifying eParticipation initiatives in our first methodological step, the next two steps were performed only in English. So, the questionnaire was in English and all communication with initiatives' owners was also performed in English. This might also explain to an extent the low response rate.

\section{Results}

The results of our survey are provided in this section. The analysis commences with information on the profile of the gathered initiatives and continues with details relevant to their participatory activities (areas and focus of participation as well as stakeholders involved), the ICT used (channels, tools and technologies) and finally an analysis of the lessons learnt.

\subsection{Initiatives Profile}

Our research sample draws experience from initiatives originating from 12 different countries across Europe; these are: Denmark, Estonia, Finland, Germany, Greece, Italy, The Netherlands, Portugal, Slovenia, Spain, Switzerland and the United Kingdom. Most of the gathered initiatives originate from Germany (10) and the United Kingdom (6).

With regard to the level of participation, the initiatives in our sample are active at all different levels; we have one international initiative and 9 initiatives referring to the European level. The rest 30 initiatives refer to specific European countries either at the national (14), regional (4) or local (12) level. Furthermore, the majority of the initiatives are reported to be driven by the public sector but other ownership types are also represented; $80 \%$ of the initiatives are initiated and owned by public authorities, bodies and organisations, while the rest $20 \%$ is owned by NGOs, private or independent institutions, Universities, or political parties.

\subsection{Use of ICT}

Another interesting feature of our sample is the presence of one or more channels supporting the participation process (Fig. 1). All of the initiatives support of course the typical internet channels, while one third of them report that they also use non electronic channels for participation. Interesting is also the usage of mobile channels (usually to involve young people), kiosks (usually to involve people without internet access) and access through other intermediaries (usually to involve people without much experience in ICT). Our survey also revealed interesting details on the ICT tools and technologies used (Fig. 2 and Fig. 3). 


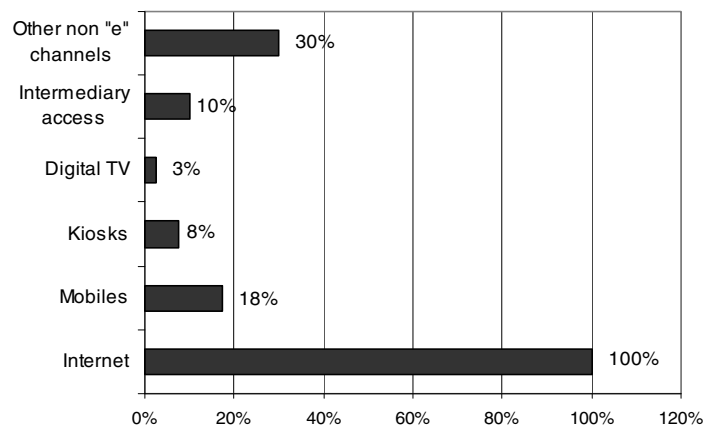

Fig. 1. Use of communication channels

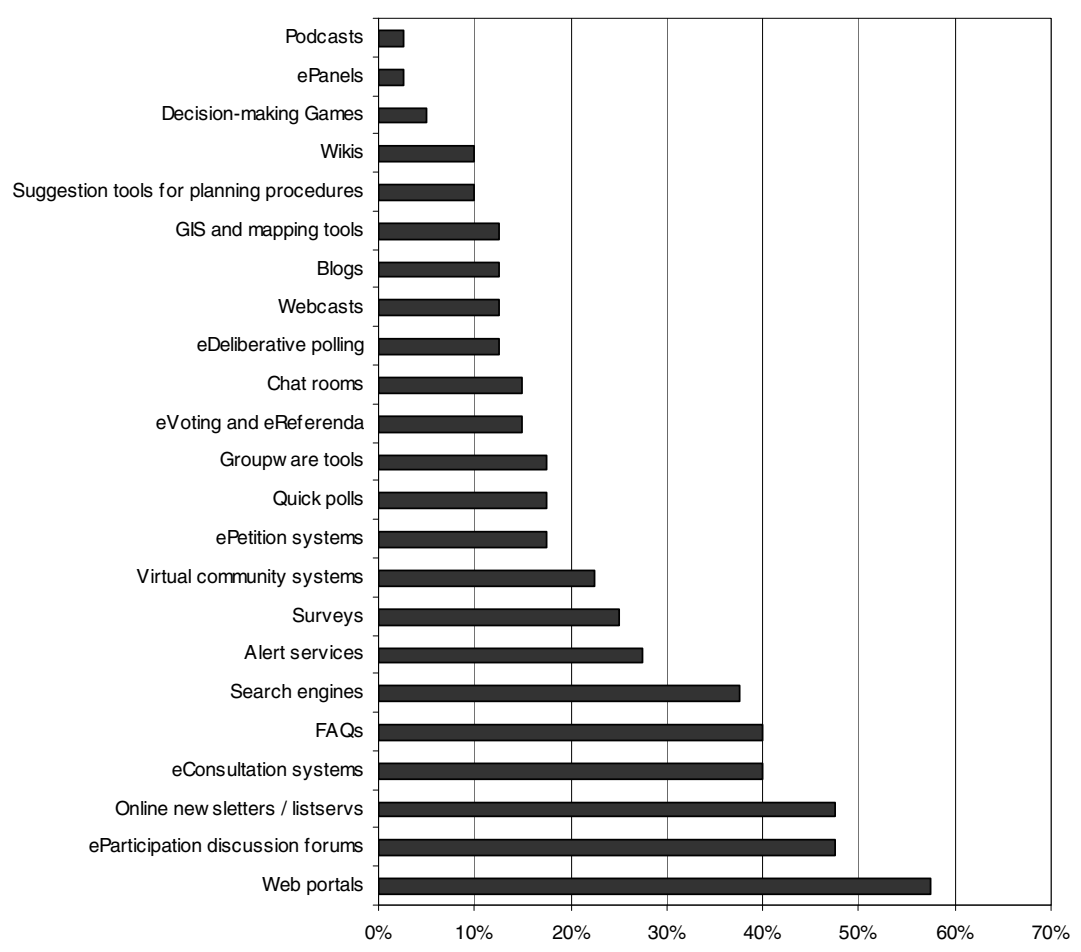

Fig. 2. Use of ICT tools

\subsection{Success Factors}

The survey questionnaire included specific questions on the problems encountered, the critical success factors and the lessons learnt. The analysis of the results reported under these questions provided an understanding that there is a certain set of issues of importance that come up in most of the reported initiatives. Clearly, one issue may be 


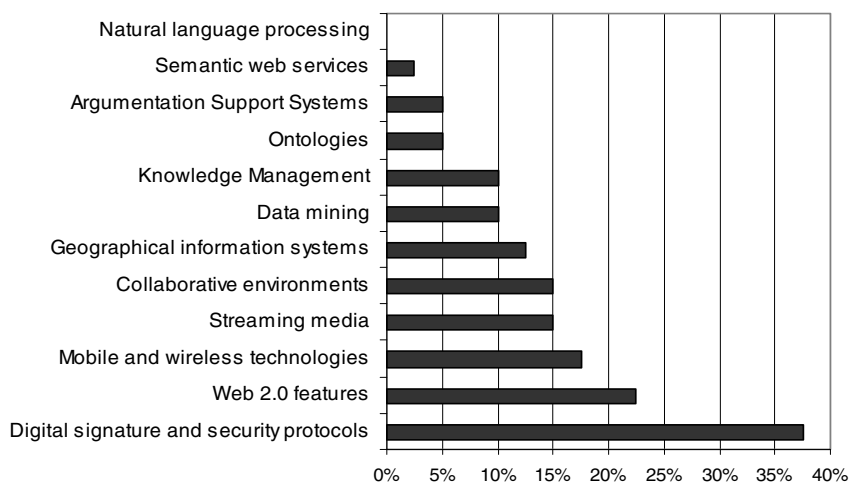

Fig. 3. Use of technologies

a problem for one initiative or a lesson learnt for another depending on a number of factors. This may depend, for example, on the design of the initiative processes, the available budget, the readiness of the different stakeholders, or simply on whether it was anticipated and thus respective proactive measures had been taken beforehand or not. In every case, the gathered bottom-up results indicated that there are essentially seven factor categories to be taken under consideration which might make an actual difference between a successful and a mediocre eParticipation initiative. This section presents the gathered feedback on each factor category and provides the relevant implications as reported by the practitioners in the field.

Commitment by the government. The actual involvement of governmental bodies and agencies not only as owners but throughout the whole participation process has been highlighted by most of the reported initiatives as a critical success factor. In specific, involvement as well as actual commitment of the government has been reported as essential in the following settings:

- Drive to set up and support the initiative. Successful initiatives set up by governmental bodies reported that there is an absolute need for champions from within the organisation to embrace and promote internally the project backed up by an actual willingness of the organisation to hold a governmentcitizen dialogue.

- Support of the participatory process. Supporting the initiative from its design to its operation and evolvement is needed from all parts of the organisation; from the officials and management down to the secretariat of every operational unit. The support may be manifested through the business integration of the relevant units/roles to the participatory process but also through means more apparent to the users, such as through actual participation of officials/appointed civil servants in the initiative (virtual presence) and physical presence in related events, meetings, etc.

- Feedback and integration of results. Participants of the initiatives reported systematically their fear that "the whole process might lead to nothing" and thus demand a clear commitment for integrating the results of the initiative 
into the political process or at least for getting feedback on the overall results of the participation and how these will be used in the future. Unfortunately, this fear is validated by experience so far; there have been otherwise remarkable initiatives which reported that indeed the involved government bodies did not provide feedback to the issues and questions raised or that they provided answers either too generic or too selective (probably only to the "easy" issues raised). Evidently, this issue is of particular importance when trying to create a climate of transparency, trust and creative interaction in the government-citizen relationship.

Usability. A lot has been already published on the importance of usability and userfriendliness for all kinds of eParticipation (and eGovernment) initiatives. And indeed our empirical analysis found that it is one of the most frequent and important success factors. Experience gathered from the owners suggests that any kind of eParticipation initiative should be really easy and intuitive for all kinds of users, from internet savvy ones to those with limited ICT skills. For this reason, it has been reported that special attention should be put into the user interface with the option of dynamic development of technical features whenever it is considered essential. Furthermore, the aims of the initiative as well as the usage rules should be clearly defined and explicitly described online for the users' convenience. Moreover, the provision of help-desk facilities was reported as a positive lesson learnt as users may request assistance with things that may at first seem trivial and straightforward. For example, in one of the initiatives it was discovered that about $5 \%$ of the people that accessed the electronic consultations portal did not finally cast their opinion due to problems with the software used. However, the need for simplicity and usability should not become a barrier for enhanced functionality; it has also been reported that users expect from such initiatives to keep in pace with technological developments and to incorporate new features used in different settings, such as more interactivity and social networking.

Combining different channels, both online and offline ones. The channels mix is an important strategic decision for any eParticipation initiative. As mentioned previously, our survey showed that eParticipation initiatives rely heavily on traditional internet access through personal PCs and laptops. However, there is a $43 \%$ of eParticipation initiatives surveyed that utilise at least one additional online or offline channel, while one third reported that they combine online with offline channels. However, the channels mix came up also as a success factor of the reported initiatives, mostly as a means to facilitate inclusiveness. Owners' experience showed that multiple channels increase the participation figures; this has been clearly measured in initiatives performing any kind of voting either official national voting or municipal and small scale voting. There are a number of citizens that cast their votes online but there are also citizens who prefer mobile voting or casting their votes in the dedicated kiosks. So, in order to raise the overall turnout experience showed that a combination of channels is needed. Another usual example of increased citizens' participation is through combining online consultation/deliberation tools with offline meetings and workshops. In overall, there has been positive feedback from the owners that did utilise a combination of channels, while others reported their plans to expand their activities to more channels apart from the typical internet access. 
A thorough communication and promotion plan. Owners in the survey referred a lot to problems and lessons regarding the need for a thorough communications plan and directly linked promotion with the actual success of the initiative. It has been reported that there is an absolute need for a detailed, professional and intensive communications strategy as well as for the will and the resources to back it up until the end. It is also important for each initiative to develop an appropriate branding including a distinct and easily recognised name and logo, but also to pay special attention to the key message that gets across to citizens (and of course live up to that message). It has been additionally proposed that there should be one dedicated resource with the aim to promote the initiative, to be in constant communication with all kinds of stakeholders and to engage in getting users on board. Of course, many different ways and channels for communication have also been proposed by owners, including advertisements in online and offline media, presence in events and workshops, even demonstrations at the road. Evidently, the right marketing mix is to be decided by each initiative after considering its own specificities.

Security and privacy. Security and privacy of users is one of the concerns that each eParticipation initiative has to face. The absolute need for security is self-evidently manifested in all initiatives that implement any kind of voting mechanisms. All such initiatives have reported that they utilise security mechanisms of different kinds and no security breaches were reported among these. However, when it comes to privacy and the degree of anonymity allowed not all owners seem to agree on a unique and ideal solution. On the one side, it has been reported in most of the initiatives that participation has been deliberately designed to be anonymous in order not to intimidate users who are concerned whether their personal information will be available online to the rest of the participants. On the other hand, it has been also reported that the fact that the contributing users are posting under their full name brings integrity to their opinions as well as an overall trust towards the whole initiative and the produced outcomes. Obviously, the ideal approach to privacy concerns depends also on the actual circumstances of each initiative, the kind of users it targets, the prestige the owner brings to the effort, etc. Nevertheless, it is a feature to be thoroughly debated and decided at the design phase.

Organisational issues. Different organisational concerns have been highlighted by the owners as success factors; these can be summarised in three broad categories: management related, process related, and moderation related.

- Management. There is consensus that strong project management is an essential component for success; a senior person should be preferably appointed as a dedicated resource responsible for the whole project's operation. Moreover, it is important to establish an effective and sustainable management process with short tasks and checkpoints and defined communication channels among the team members. Finally, the need for generous timescales and contingency planning has been also highlighted; managers should allow sufficient time for planning and implementation and should try to exploit previous experience in the field (i.e. lessons learnt, replication of tested methods and tools, etc.) 
- Processes. Processes are of particular importance in eParticipation as the whole initiative should offer an end-to-end effective, satisfying and timely experience. Processes planning starts from the initial conceptualising phase when certain considerations and decisions have to be made. For example, owners stressed the importance of taking into consideration the particular needs and circumstances of the targeted audience (i.e. with regards to internet usage patterns, ICT skills, cultural and political specificities, etc.) and devising a tailor-made participation methodology to fit the purposes of the initiative at hand. Clearly, the ultimate intention is to achieve inclusiveness (i.e. by ensuring that relevant special audiences and minority groups are also considered) and a balanced participation and user engagement to the best possible degree. Moreover, experience showed that active two-way communication between operators and users of the initiatives is a must; it is proposed that tools for users' comments and contact are kept as simple as possible and that users are involved in the development/enhancement process. Finally, clear and realistic business processes are need to be put in place for ensuring that all different roles/departments provide relevant content/feedback in due time and according to the promises made to the participants.

- Moderation. All reported initiatives agree on the need for a heavy, active and timely moderation. Moderators need adequate training in order to be able to support and promote open, serious, and high quality participation while they should also possess sufficient awareness of participation principles and practices in order to identify and tackle inevitable difficulties such as the conscious or unconscious domination of the discussion by some extremely active users. In overall, moderation plays an important role in keeping up the commitment and enthusiasm of users.

Topics complexity and quality of participation. Finally, it was reported that the technocratic and legislative complexity as well as the limited knowledge and expertise of users prevented a deep deliberation on the issues at hand limiting thus participation at a superficial and trivial level. Moreover, the fact that many participants did not appear ready to be involved in productive dialogue and they rather preferred to generally express opinions, personal view points or convictions, which were rarely supported by informed arguments, deteriorated the situation. It was therefore suggested that a preliminary processing of the data under discussion to make it understandable by non-experts would be a solution to the aforementioned issue.

\section{Discussion and Conclusions}

Electronic Participation has recently evolved to re-engage people with the democratic processes by exploiting the potential of ICT. At the academic level, a number of frameworks and models have been proposed for understanding eParticipation including evaluating relevant initiatives. At the practical level, a large number of eParticipation initiatives have been launched at all levels, some with success while others without. 
In this paper, we investigate the use of ICTs and the main success factors of eParticipation initiatives according to the practitioners' perspective. For that purpose, we conducted an extensive European study and obtained information using a questionnaire that was developed for this purpose based on the relevant literature.

A first observation of this study is the low response rate of returned questionnaires. This may be due to the fact that some initiatives have officially ended, due to the significant length of the questionnaire or due to the language of communication (English). On the other hand, the different media used by the research team (e.g. email, telephone, fax) for a long period of time and the nature of the initiatives (eParticipation) allowed us to hope for better response at the beginning of our study.

With regards to the communication channel employed, the Internet is the dominant medium (100\%) while a significant percentage of initiatives $(30 \%)$ employs non electronic channels in combination with electronic ones. In terms of ICT tools, portals, plain discussion forums, online newsletters and eConsultation systems are the prominent players. This suggests that eParticipation initiatives mainly use existing, general-purpose ICT tools (which are sometimes tailored) and not eParticipation-specific tools. In terms of technologies, security seems a clear concern while general-purpose developed technologies (such as Web 2.0, mobile and wireless technologies, and streaming media) dominate the field with eParticipation-specific technologies lagging behind.

The results of this study also indicated seven main success factor categories according to the practitioners' perspective. These are commitment by the government; usability; combining online with offline channels; a thorough communication and promotion plan; security and privacy; organisational issues; and topics complexity and quality of participation. In the relevant literature, academics have recently attempted to identify success factors and barriers in the context of electronic Government (eGovernment). Summarising existing work, Gilbert and Balestrini suggest benefits which include: avoid personal interaction, control over service delivery, convenience, cost, personalization and time, while barriers for adoption include confidentiality, easy to use, enjoyable, reliable, safe and visual appearance [15]. Similarly, Ebrahim and Irani [16] suggest eGovernment barriers which include IT infrastructure, security and privacy, IT skills, organisational (e.g. unclear vision, lack of communication between departments etc) and operational cost. In a first attempt to put our results in the context of relevant eGovernment work, we note that there are certain factors which are common, such as usability, security and privacy. On the other hand, it should be noted that there are certain factors deemed particularly important for eParticipation practitioners, which do not seem to deserve particular attention in eGovernment. These include combining online with offline channels, having a thorough communication and promotion plan as well as topics complexity and quality of participation. In addition, organisational aspects in eParticipation have somehow a different orientation as besides project management they also include participatory processes and moderation which are unique to eParticipation. In depth investigation of similarities and differences between eGovernment and eParticipation success factors is outside the scope of this paper and is left for future work as our initial results indicate there might be considerable differences.

Acknowledgments. Work presented in this paper has been partially funded by the EU through the European eParticipation study (http://islab.uom.gr/eP/). 


\section{References}

1. Macintosh, A.: eParticipation in policy-making: the research and the challenges. In: Exploiting the Knowledge Economy: Issues, Applications. Case Studies. IOS Press, Amsterdam (2006) ISBN 1-58603-682-3

2. Communication from the Commission to the Council, the European Parliament, the European Economic and Social Committee and the Committee of the Regions: i2010 eGovernment Action Plan: Accelerating eGovernment in Europe for the Benefit of All. Commission of the European Communities, Brussels (2006)

3. Barber, B.: Strong democracy: Participatory politics for a new age. University of California Press, Berkeley (1984)

4. Coleman, S., Gøtze, J.: Bowling Together: Online Public Engagement in Policy Deliberation. Hansard Society, London (2001),

http: / / bowlingtogether. net/bowlingtogether.pdf

(accessed March 30, 2010)

5. Macintosh, A.: Characterizing E-Participation in Policy-Making. In: 37th International Conference on System Science, Hawaii (2004)

6. Kalampokis, E., Tambouris, E., Tarabanis, K.: A Domain Model for eParticipation. In: Third International Conference on Internet and Web Application and Services, Athens (2008)

7. Smith, S., Macintosh, A., Millard, J.: eParticipation Analytical Framework. European eParticipation Study deliverable (2008),

http: / / www . european-eparticipation. eu (accessed March 30, 2010)

8. Aichholzer, G., Allhutter, D.: Evaluation Perspectives and Key Criteria in eParticipation. In: 6th International Eastern European eGov Days: Results and Trends (2008)

9. Rowe, G., Frewer, L.: Public Participation Methods: A Framework for Evaluation. Science, Technology and Human Values 25(1), 3-29 (2000)

10. Tambouris, E., Liotas, N., Tarabanis, K.: A framework for Assessing eParticipation Projects and Tools. In: 40th Hawaii International Conference on System Sciences, Hawaii (2007)

11. Macintosh, A., Whyte, A.: Towards an Evaluation Framework for eParticipation. Transforming Government: People, Process \& Policy 2(1) (2008)

12. DEMO-net Consortium: D13.3 DEMO-net booklet: eParticipation Evaluation and Impact (2008), http: / /www. demo-net . org (accessed March 30, 2010)

13. Panopoulou, E., Tambouris, E., Tarabanis, K.: eParticipation good practice cases and diffusion. European eParticipation Study deliverable (2008),

http: / / www . european-eparticipation. eu (accessed March 30, 2010)

14. Panopoulou, E., Tambouris, E., Tarabanis, K.: eParticipation initiatives: How is Europe progressing? European Journal of ePractice (2008), http: / / www . epracticejournal . eu (accessed March 30, 2010)

15. Gilbert, D., Balestrini, P.: Barriers and benefits in the adoption of e-government. The International Journal of Public Sector Management 17(4), 286-301 (2004)

16. Ebrahim, Z., Irani, Z.: E-government adoption: architecture and barriers. Business Process Management Journal 11(5), 589-611 (2005) 


\section{Appendix}

This appendix provides the list of eParticipation initiatives included in this research. It should be noted that the names of five initiatives do not appear in the table below because the owners have wished for their feedback to remain anonymous. However, the feedback gathered by these initiatives has been included in the analysis.

\begin{tabular}{|l|l|l|}
\hline eParticipation initiative & & Scope \\
\hline Aarhus Clearinghouse for Environmental Democracy & World & International \\
\hline Debate Europe & EU & European \\
\hline European Citizens' Consultations & EU & European \\
\hline European Ombudsman & EU & European \\
\hline Fundamental Rights Agency & EU & European \\
\hline Website of Commissioner Almunia & EU & European \\
\hline $\begin{array}{l}\text { Portal for the involvement of civil society in the Slovenian presidency } \\
\text { of the EU }\end{array}$ & Slovenia & European \\
\hline Rostra & Denmark & National \\
\hline Internet Voting in Estonia & Estonia & National \\
\hline Osale.ee & Estonia & National \\
\hline Environmental Information Portal PortalU & Germany & National \\
\hline Kommunalforum.de - City administration network & Germany & National \\
\hline Online Consultation "Citizen's Portal Draft Bill" & Germany & National \\
\hline e-pnyka.gr & Greece & National \\
\hline Virtual Cities & Netherlands & National \\
\hline The Citizen's Forum & Slovenia & National \\
\hline Geneva Internet Voting Application & Switzerland & National \\
\hline iVote.ch & Switzerland & National \\
\hline e-consultant & UK & National \\
\hline Food Standards Agency Blog & UK & National \\
\hline eParticipation for the Regional Land Use Plan Frankfurt/Rhine-Main & Germany & Regional \\
\hline Senso@Iternato & Italy & Regional \\
\hline kNOWing & Portugal & Regional \\
\hline Bus Stop 34 & UK & Regional \\
\hline Living Bridge & Germany & Local \\
\hline Metropole Hamburg - Growing City & Germany & Local \\
\hline Participatory Budgeting Freiburg & Germany & Local \\
\hline Participatory Budgeting Hamburg & Germany & Local \\
\hline Re-design of the Domplatz & Germany & Local \\
\hline e-dialogos & Greece & Local \\
\hline Turin Multimedia Channel & Italy & Local \\
\hline Madrid-p & Spain & Local \\
\hline 21st Century Voting in Sheffield & UK & Local \\
\hline Kingston Upon Thames ePetitions & UK & Local \\
\hline Swindon Electoral Modernisation Programme & UK & Local \\
\hline & & \\
& & \\
\hline
\end{tabular}

